[Agr. Biol. Chem., Vol. 35, No. 5, p. 764 777, 1971]

\title{
Metabolism of the Herbicide 3-(2'-Methylphenoxy) pyridazine in Plants
}

\author{
By Masayuki NaKagawa, Katsuhiko KaWAKUBo \\ and Mitsuo ISHIDA \\ Sankyo Co., Lid., Agricultural Chemicals Research Laboratories \\ 2-58, 1-chome, Hiromachi, Shinagawa-ku, Tokyo, Japan \\ Received October 17, 1970
}

\begin{abstract}
Absorption and metabolism of the herbicide 3-(2'-methylphenoxy)pyridazine ( $\mathbf{H}-722)$ by susceptible (barley) and tolerant (tomato) plants were investigated with a tritium labeled chemical to obtain fundamental information on residue analysis as well as on selective action. Four metabolites were clearly detected, for which chemical structures were assigned, except a minor one. They were 3-(2'-methylphenoxy)pyridazine-1-oxide, 3-pyridazinone$(2 \mathrm{H})$ and $3-(1-\beta-\mathrm{D}-\mathrm{glucosyloxy})$ pyridazine. The fate and behavior of o-cresol which should be a metabolite resulting from cleavage of the aromatic ether linkage in $\mathrm{H}-722$ is considered a key to the mechanism of the herbicide's selective action.
\end{abstract}

3-Phenoxypyridazines are pre-emergence herbicides as described by Jojima et al. ${ }^{11}$ They have been shown to have effective action toward the grasses (Graminaceae), e.g, barnyardgrass. ${ }^{2}$ In our country, one of these chemicals, 3- $\left(2^{\prime}\right.$-methylphenoxy) pyridazine $(\mathrm{H}-722)$ is known as a promising herbicide for use on paddy fields, since this chemical generally completely kills both barnyardgrass and spikerush at the rate of $50 \mathrm{~g}$ per $10 \mathrm{a}$ without injury to transplanted rice plants. ${ }^{21}$

For field crops, these chemicals have become the objects of attention especially for tomato, soybean and cotton fields, since they have shown remarkable herbicidal activity without injury to these useful crops. ${ }^{3 !}$

In this study, metabolism of $\mathrm{H}-722$ in susceptible (barley) and tolerant (tomato) plants was investigated with 6 -tritium-3-(2'-methyl-

1) T. Jojima, K. Oyamada and S. Tamura, Agr. Biol. Chem., 32, 1376 (1968).

2) T. Jojima, N. Yoshimura, T. Takematsu and $\mathrm{S}$. Tamura, ibid., 33, 96 (1969).

3) K. Kawakubo of Sankyo Co., Ltd., Unpublished Work. phenoxy)pyridazine, to obtain fundamental information for residue analysis, as well as for elucidation of the mechanism of its selective action.

\section{MATERIALS AND METHODS}

Chemicals. 6-T-3-(2'-Methylphenoxy) pyridazine was synthesized by the Radiochemical Center, London, England, through catalytic reduction of 6-chloro-3(2'-methylphenoxy)pyridazine with tritium gas after Jojima's method.1 After purification by silica gel column chromatography and repeated recrystallization, the specific activity was adjusted to $2.0 \mathrm{mCi} / \mathrm{mg}$ with the unlabeled chemical. No radiochemical impurities were detectable by thin-layer chromatography. In some experiments, the radioactive chemical was further diluted with an unlabeled one. 3-Pyridazinone$(2 \mathrm{H})$, mp $70.5 \sim 71.5^{\circ} \mathrm{C}$, and $3-\left(2^{\prime}\right.$-methylphenoxy) pyridazine-1-oxide, mp $117.5 \sim 119^{\circ} \mathrm{C}$, were provided by $\mathrm{T}$. Jojima of our laboratories. Reagent grade maleic hydrazide was purchased. 2-(I- $\beta$-D-Glucosyl) pyridazinone-(3), mp $218 \sim 220^{\circ} \mathrm{C}$, and $3-(1-\beta-\mathrm{D}-$ glucosyloxy) pyridazine, $\mathrm{mp} 163 \sim 165^{\circ} \mathrm{C}$, as well as their tetra-acetyl derivatives ( $\mathrm{N}$-type $\mathrm{mp} 153 \sim 154^{\circ} \mathrm{C}, 0$-type mp $173 \sim 175^{\circ} \mathrm{C}$ ), were synthesized in our labora- 
tory after Wagner's method.4 Dowex 50 -W-X8 was used instead of Wofatit KPS p.a. for neutralization of sodium methoxide used for deacetylation of 2-

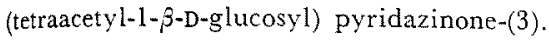

Determination of radioactivity. Radioactivity was measured by liquid scintillation counting 5 , with a Packard Tri-Carb Liquid Scintillation Spectrometer, Model 3002. The scintillation solution used was 8.0 $\mathrm{g}$ of PPO plus $200 \mathrm{mg}$ of dimethyl-POPOP in a mixture of $800 \mathrm{ml}$ dioxane and $200 \mathrm{ml}$ toluene. Counting efficiency for each sample was determined by addition of the standard tritiated toluene.

Plant materials and treatments. Barley (Hordeum vulgare L. var. Akashinriki) and tomato (Lycopersican esculentum Mill var. Fukuju No. 2) plants were germinated and grown in soil contained in flats $(50 \mathrm{~cm} \times$ $40 \mathrm{~cm}$ ) in a greenhouse. After plants reached the 1st to 2nd leaf stage of growth, they were transferred to jars containing Knop's solution. Two days were allowed for adaptation to the new conditions, then treatment was started. After exposure, treated plants were washed thoroughly in acetone and tap water, and then they were surfacedried and weighed. Plants were separated into shoot and root, each tissue was homogenized with a glass homogenizer in ethanol, then filtered through a glass filter. The filtrate was evaporated almost to dryness at $45 \sim 50^{\circ} \mathrm{C}$ in vacuo. The evaporation procedure was performed in every experiment when isotope recovery was determined, to remove tritiated water which might have been produced in plants during the exposure period. The evaporation residue was dissolved in ethanol and made up to volume for measuring radioactivity. Sediments on the glass filter were dried, then a portion of them was burned in a Schoeniger flask and the resulting tritiated water was measured.

For experiments during the germination stage of plants, 30 seeds were planted in $8 \mathrm{~cm}$ deep, $9 \mathrm{~cm}$ (I.D.) Petri dishes containing $10 \mathrm{ml}$ of $1 \mathrm{ppm} \mathrm{H}-722$ $(2.0 \mathrm{mGi} / \mathrm{mg})$ dissolved in the nutrient solution. Dishes were kept in the dark at $26^{\circ} \mathrm{C}$ during the germination periods. In these cases, the whole plants were homogenized without separation into shoot and root.

Separation of $H-722$ and its metabolites. Thin-layer

4) G. Wagner and D. Heller, Archiv. der Pharmazie, 299, 208 (1966).

5) F. E. Butler, Anal. Chem., 33 409, (1961). chromatography was extensively employed using $20 \times$ $20 \mathrm{~cm}$ glass plates coated with silica gel G (Merck $0.25 \mathrm{~mm}$ ) previously washed with acetone and methanol, or using Eastman Chromatogram Sheet 6061 for autoradiography. Plates were developed ascending for $10 \mathrm{~cm}$. Solvents systems used were (A) benzene: ethanol: chloroform $(1: 2: 2, \mathrm{v} / \mathrm{v} / \mathrm{v})$, (B) $n$-butanol: acetic acid: water $(4: 1: 5, v / v / v)$. In some experiments, (C) $n$-hexane: acetone: diethyl ether $(1: 1: 1, v / v / v)$ was used with the glass plate to develope mobile chemicals, and the radioactivity remaining at the origin was eluted from the silica gel with methanol and spotted on another plate for development in solvent system B. After development, 0.5 to $1.0 \mathrm{~cm}$ portions of the silica gel from the origin to the solvent front were scraped from the plates, and each portion was counted. This method was considered satisfactory because good separation was obtained as shown in Table I. Approximately 90\%; of the radioactivity which originally spotted was recovered from the plates. Radiochemical isolation of the metabolites was accomplished by this method.

Petri dish method for the estimation of herbicidal activity. Duplicate samples of 10 seeds of each species were placed in $9 \mathrm{~cm}$ Petri dishes. Five $\mathrm{ml}$ of sample solution was added. After a soaking and germination period of 6 days at $26^{\circ} \mathrm{C}$ in the dark, radicles and shoots were measured.

Exchangeabilities of tritium in $\mathrm{H}-722$ and some metabolites with hydrogen of water. Each metabolite radiochemically isolated by TLC or $\mathrm{H}-722$ was dissolved in $0.2 \mathrm{ml}$ of sterilized water containing $5 \%$ ethanol, then it was put into the upper part of sterilized Thunberg tube as shown in Fig. 1. Addition of the alcohol was for inhibition of metabolism by microorganisms which might have contaminated the components tested. After standing for thirty days at room temperature, the lower part of the apparatus was cooled with a dryice-acetone bath for five days to condense the water. Condensed water at the bottom of the tube and materials remaining in the upper part of the tube were placed in counting vials by rinsing them with the scintillation solution.

Hydrolysis of one of the metabolites (M3). Radiochemically isolated M3 was hydrolyzed for 3 hr on a steam bath with $1 \mathrm{~N}$ hydrochloric acid or $1 \mathrm{~N}$ sodium hydroxide. Enzymatic hydrolysis with $\beta$-glucosidase (Sigma Chemical Co., St. Louis, Mo., U.S.A.), in 
$0.1 \mathrm{M}$ citric acid-phosphate buffer ( $\mathrm{pH} 4.6$ ), was also carried out at $37^{\circ} \mathrm{C}$ for $4 \mathrm{hr}$.

Isolation of unknown metabolites. Isolation and identification of the metabolites were conducted with barley. About $50 \mathrm{~kg}$ fresh weight of barley material in the Ist to 2nd leaf stage grown in soil was washed thoroughly with tap water to remove soil. Roots were dipped in nutrient solution containing $50 \mathrm{ppm}$ unlabeled $\mathrm{H}-722$. After 5 days barley shoots were collected and homogenized in ethanol with a Waring blender. Liquid was squeezed out with a double layer of cheesecloth, then it was condensed in vacuo at $45 \sim 50^{\circ} \mathrm{C}$. The aqueous concentrate was treated with charcoal for $1 \mathrm{hr}$ at room temperature. Substances adsorbed on the charcoal were eluted 3 times each with acetone, and $90 \%$ methyl ethyl ketone at room temperature. All eluates were collected and concentrated in vacuo at $45 \sim 50^{\circ} \mathrm{C}$. The aqueous concentrate was extracted with ethylacetate after adjustment to $\mathrm{pH} 3$ with $2 \mathrm{~N}$ hydrochloric acid, then to $\mathrm{pH} 10$ with $4 \mathrm{~N}$ ammonium hydroxide to remove soluble materials. The ethylacetate layer was stored in 1 refrigerator for the later isolation of metabolite M1.

The aqueous layer was evaporated to dryness in vacuo, and methanol was added to the residue to remove an insoluble precipitate. After filtration, the methanol was evaporated and a mixture of radiochemically isolated M2 and M3 was added to the residual materials. Further purification procedures were performed using the isotope tracing method. Residual materials were dissolved in a small volume of water, then adjusted to $\mathrm{pH} 3$ with dilute hydrochloric acid and put onto a column of Dowex 50W$\mathrm{X} 8\left(\mathrm{H}^{+}\right.$form, $\left.100 \sim 200 \mathrm{mesh}\right)$. The column was washed with water until the effluent became neutral, then it was eluted with $1 \mathrm{~N}$ ammonium hydroxide. M2 was detected in acidic fractions, while M3 was eluted by the alkaline solution. Fractions containing M2 and M3 were evaporated in vacuo. The M2 fraction was column chromatographed $(3 \times 50 \mathrm{~cm})$ with silica gel $(100 \sim 200$ mesh) using $n$-hexane: diethyl ether: acetone $(1: 1: 1, v / v / v)$ as the solvent system. Most of the colored material remained at the top of the column. After evaporation, materials eluted from

Table I. TlC $R f$ Values of H-722 and its Related Compounds

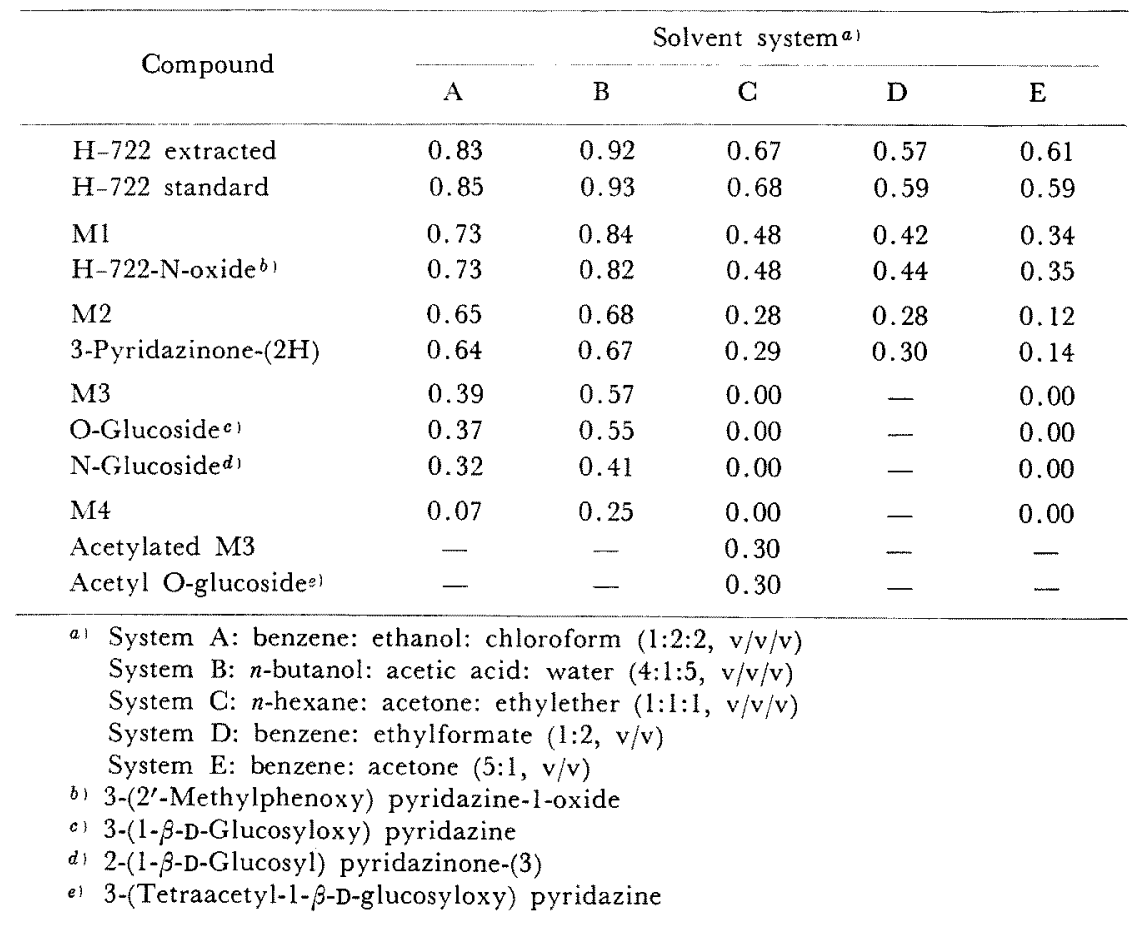




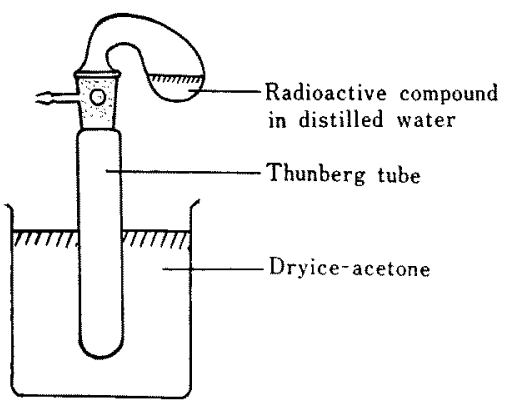

Fig. 1. Apparatus for Experiments on Exchangeability of Tritium in $\mathrm{H}-722$ and its Related Compounds with the Hydrogen of Water.

the silica gel column were dissolved in a small volume of water and filtered through a column of Sephadex G-10 $(2 \times 30 \mathrm{~cm})$ with water. The remaining colored materials were adsorbed on the Sephadex, to some extent, while recovery of M2 was almost complete. M2 fractions were evaporated in vacuo, and were finally purified by thin-layer chromatography with system C and D (Table I).

For purification of M3, silica gel column chromatography $(4 \times 80 \mathrm{~cm}, 100 \sim 200$ mesh) eluted with benzene: ethanol: chloroform $(1: 2: 2, \mathrm{v} / \mathrm{v} / \mathrm{v})$ and Sephadex $\mathbf{L H} 20$ column chromatography $(2 \times 40 \mathrm{~cm})$ eluted with methanol were successively performed. The latter column chromatography was repeated 4 times, since a brownish rather sticky material was incompletely separated from M3 in each cycle. Sephadex G-10 gel filtration $(2 \times 30 \mathrm{~cm})$ with water was the next step of purification. This procedure was performed 3 times, mainly to remove the remaining colored sticky material by adsorption on the Sephadex. Isotope recovery was almost complete in both types of chromatography. The aqueous fraction of M3, after adjustment to $\mathrm{pH} 3$ with dilute hydrochloric acid, was adsorbed on a column of Dowex $50 \mathrm{~W}-\mathrm{X} 8(2 \times 20 \mathrm{~cm})$. It was washed with water until the effluent became neutral, then eluted stepwise with $60 \mathrm{ml}$ each of $0.1 \mathrm{~N}, 0.3 \mathrm{~N}, 0.4 \mathrm{~N}, 0.6 \mathrm{~N}$ and $0.8 \mathrm{~N}$ ammonium hydroxide. M3 started eluting with the $0.6 \mathrm{~N}$ base ( $\mathrm{pH} 10$ ). The radioactive fraction was then purified by descending paper chromatography on Toyoroshi No. $51 \mathrm{~A}$ with $n$-butanol: acetic acid: water $(4: 1: 5, v / v / v), 3$ times. Radioactive bands were subsequently extracted with boiling methanol. The resulting slightly colored syrup was acetylated. Five drops each of pyridine and acetic anhydride were added to the syrup and the whole was cooled in an ice water bath and allowed to stand overnight, to reach room temperature. Contents were purified by TLC with system $\mathrm{C}$.

To isolate Ml, the evaporation residue of the ethylacetate layer was dissolved in water and extracted with chloroform at $\mathrm{pH} 3$ and $\mathrm{pH} 10$. The solvent layer, after evaporation, was subjected to silica gel column chromatography with chloroform, then to TLC with system C and D.

\section{RESULTS}

\section{Absorption and translocation}

Time-course experiments showed that $\mathrm{H}-722$ was readily absorbed by both species and was translocated to the leaves. Isotope recoveries were about $85 \%$ to $90 \%$ with both species.

TABle II. Time Course Experiments on the Up-TAKe and Translocation of H3-Labeled H-722 IN BARLEY AND TOMATO SEEDLINGS

\begin{tabular}{ccccccccc}
\hline Plant ${ }^{\alpha}$ ( & $\begin{array}{c}\text { Time after } \\
\text { treatment } \\
\text { (hr) }\end{array}$ & $\begin{array}{c}\text { Fresh } \\
\text { Shoot }\end{array}$ & Root & Feeding soln. & Shoot & Root & Total & $\begin{array}{c}\text { Recovery } \\
(0)\end{array}$ \\
\hline \multirow{4}{*}{ Barley } & 24 & 1.9 & 0.4 & 164.4 & 21.0 & 3.6 & 189.0 & 90.0 \\
& 48 & 2.1 & 0.4 & 126.2 & 56.8 & 5.9 & 188.9 & 89.9 \\
& 72 & 2.3 & 0.5 & 115.2 & 63.3 & 4.0 & 182.5 & 86.9 \\
Tomato & 24 & 2.3 & 0.2 & 151.8 & 32.6 & 3.3 & 187.7 & 89.3 \\
& 48 & 2.7 & 0.3 & 104.6 & 70.5 & 5.2 & 180.3 & 85.8 \\
& 72 & 2.9 & 0.4 & 87.4 & 88.6 & 3.3 & 179.3 & 85.4 \\
\hline
\end{tabular}

a) Five plants in each group. Concentration of the chemical was $1.5 \mathrm{ppm}(2.0 \mathrm{mCi} / \mathrm{mg})$ in $30 \mathrm{ml}$ of $\mathrm{Knop}$ 's solution. 
Fluctuations of the recovery ratio were not correlated with treatment time in either species (Table II). Similar results were obtained from experiments at different concentrations of H-722 (Table III). In all experiments, tomato seedlings were observed to have a much stronger tendency to absorb the chemical than did barley, when compared on a fresh weight basis (Table III and V). In the germination stage, barley absorbed the chemical more than tomato did in comparison with a unit seed quantity (Table IV). This result may be attributable to the difference in sizes and weights of the seeds of the two species.
When compared on a dry weight basis, the absorption rate of tomato was greater than barley under the same conditions as shown in Table VI.

In germination stage of barley there was almost no difference in absorption and metabolism for the two treatment periods (Tables IV and VI). This suggests that some vital functions of barley were already considerably inhibited after 4 days of exposure. Isotope recoveries in the germination stages of both species reached $95 \%$ or more (Table IV).

These results indicate that neither absorption nor translocation factors have any rela-

Table III. Distribution of Radioactivity in Barley and Tomato Seedlings Grown for 5 Days in Various Concentrations of H3$^{3}$-LABELED H-722 SOLution

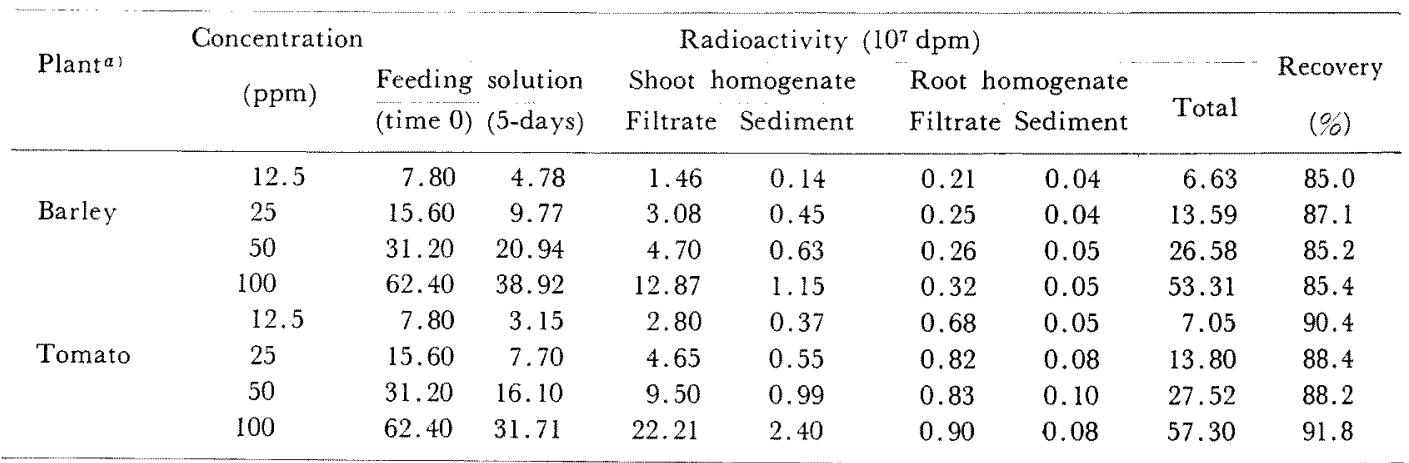

a) Thirty grams (fresh weight) of the plants in each group. $100 \mathrm{ml}$ of feeding solution (Knop's solution) containing $\mathrm{H}-722(25 \mu \mathrm{Ci} / \mathrm{mg})$ was used for each group.

Table IV. Distribution of Radioactivity in the Germination Stage of Barley and TOMATO TREATED WITH H-722 FOR 4 AND 7 DAYS

\begin{tabular}{|c|c|c|c|c|c|}
\hline \multirow{3}{*}{ Plantal } & \multirow{3}{*}{$\begin{array}{c}\text { Time after } \\
\text { treatment } \\
\text { (day) }\end{array}$} & \multicolumn{3}{|c|}{ Radioactivity ( $\left.10^{7} \mathrm{dpm}\right)$} & \multirow{3}{*}{$\begin{array}{c}\text { Recovery } \\
(\%)\end{array}$} \\
\hline & & \multirow{2}{*}{$\begin{array}{l}\text { Feeding } \\
\text { solution }\end{array}$} & \multicolumn{2}{|c|}{ Plant homogenate } & \\
\hline & & & Filtrate & Sediment & \\
\hline \multirow{3}{*}{ Barley } & 0 & 4.16 & - & - & - \\
\hline & 4 & 1.98 & 2.02 & 0.03 & 96.8 \\
\hline & 7 & I. 86 & 2.02 & 0.04 & 94.2 \\
\hline \multirow{3}{*}{ Tomato } & 0 & 4.16 & - & - & - \\
\hline & 4 & 3.64 & 0.40 & 0.01 & 97.3 \\
\hline & 7 & 2.88 & 1.18 & 0.01 & 97.8 \\
\hline
\end{tabular}

a) Thirty seeds of the plants in each group. $10 \mathrm{ml}$ of feeding solution (Knop's solution) containing $1 \mathrm{ppm}$ of $\mathrm{H}-722(2.0 \mathrm{mCi} / \mathrm{mg})$ was used for each group. 
Table V. Metabolite Composition in the Filtrate of Shoot Tissue Homogenates of SeEdings Treated with Various Concentrations of H-722 for 5 Days

\begin{tabular}{|c|c|c|c|c|c|c|c|}
\hline \multirow{2}{*}{ Plant ${ }^{a}$} & \multirow{2}{*}{$\begin{array}{l}\text { Concentration } \\
\text { of } \mathrm{H}-722(\mathrm{ppm})\end{array}$} & \multirow{2}{*}{$\begin{array}{l}\text { Total radio- } \\
\text { activity }\end{array}$} & \multicolumn{5}{|c|}{. Composition of metabolites } \\
\hline & & & $\mathrm{H}-722$ & M1 & $\mathrm{M} 2$ & M3 & M4 \\
\hline \multirow{3}{*}{ Barley } & 12.5 & 6.06 & 47.5 & 3.5 & 7.4 & 41.3 & 0.3 \\
\hline & 25 & 12.81 & 63.7 & 2.9 & 5.2 & 28.0 & 0.2 \\
\hline & 50 & 19.56 & 68.1 & 2.7 & 4.4 & 24.6 & 0.2 \\
\hline \multirow{5}{*}{ Tomato } & 100 & 53.63 & 72.5 & 2.4 & 3.7 & 21.3 & 0.1 \\
\hline & 12.5 & 9.98 & 54.0 & 11.7 & 20.6 & 13.2 & 0.5 \\
\hline & 25 & 16.59 & 58.8 & 11.5 & 17.4 & 12.0 & 0.3 \\
\hline & 50 & 33.92 & 69.3 & 4.2 & 15.4 & 10.7 & 0.4 \\
\hline & 100 & 79.28 & 76.1 & 3.4 & 13.1 & 7.2 & 0.2 \\
\hline
\end{tabular}

a) Each sample is the one shown in Table III.

b) $10^{5} \mathrm{dpm} / \mathrm{g}$ fresh weight.

table VI. Metabolite Composition in the Filtrate of Whole Plant homogenates of Barley and Tomato Treated with H-722 at the Germination Stage FOR 4 AND 7 DAYS

\begin{tabular}{|c|c|c|c|c|c|c|c|c|}
\hline \multirow[b]{2}{*}{ Plant ${ }^{a)}$} & \multirow{2}{*}{$\begin{array}{l}\text { Days after } \\
\text { treatment }\end{array}$} & \multirow{2}{*}{$\begin{array}{l}\text { Sample dry } \\
\text { weight (mg) }\end{array}$} & \multirow{2}{*}{$\begin{array}{l}\text { Total radio- } \\
\text { activity }\end{array}$} & \multirow[b]{2}{*}{$\mathrm{H}-722$} & \multicolumn{3}{|c|}{$9_{0}$ Composition of metabolites } & \multirow[b]{2}{*}{$\mathrm{M} 4$} \\
\hline & & & & & Ml & $\mathrm{M} 2$ & M3 & \\
\hline \multirow[t]{2}{*}{ Barley } & 4 & 650 & 3.15 & 34.6 & 5.5 & 7.2 & 52.6 & 0.1 \\
\hline & 7 & 650 & 3.17 & 29.9 & 5.2 & 5.5 & 59.3 & 0.1 \\
\hline \multirow[t]{2}{*}{ Tomato } & 4 & 110 & 3.73 & 59.8 & 7.7 & 7.3 & 25.0 & 0.2 \\
\hline & 7 & 210 & 5.67 & 38.1 & 15.7 & 14.7 & 31.3 & 0.2 \\
\hline
\end{tabular}

a) Each sample is the one shown in Table IV.

b) $10^{7} \mathrm{dpm} / \mathrm{g}$ dry weight.

tionship to the mechanism of selective action of $\mathrm{H}-722$, since $\mathrm{H}-722$ was readily translocated from roots to leaves. One reason for the unavailability of this compound as a postemergence herbicide by treatment of leaves of sensitive plants may be due to its poor penetration action through leaves.

Exchangeability of tritium in $\mathrm{H}-722, \mathrm{Ml}, \mathrm{M} 2$ and $M 3$ with hydrogen of water

H-722 and the major metabolites described below were examined. Each of their exchangeabilities was small enough to be neglected in considerations of the completeness of isotope recovery in all experiments described in this text (Table VII). This suggests that some metabolism, which attacks the tritium labeled
TABLE VII. EXCHANGEABILITIES OF TRITIUM IN H-722 AND ITS METABOLITES WITH THE HYDROGEN OF WATER

\begin{tabular}{cccc} 
Compound & \multicolumn{2}{c}{ Radioactivity (dpm) } & $\begin{array}{c}\text { Percentage } \\
\text { radioactivity } \\
\text { in aqueous } \\
\text { solution (?ó) }\end{array}$ \\
\hline H-722 & 69950 & 830 & 1.2 \\
Ml & 36610 & 1710 & 4.7 \\
M2 & 32320 & 570 & 1.8 \\
M3 & 27130 & 780 & 2.9
\end{tabular}

position in $\mathrm{H}-722$, might occur if relatively poor isotope recoveries were realized.

Hydrolysis of $M 3$

Hydrolysis of M3 by acid, alkali, and $\beta-$ 
glucosidase gave the same degradation product detected by radioactivity, which was chromatographically assigned as 3-pyridazinone- $(2 \mathrm{H})$. The rate of hydrolysis reached approximately $85 \%$ under acidic conditions and $75^{\circ}$ o with the alkali. Enzymatic hydrolysis by $\beta$-glucosidase was nearly quantitative. An authentic sample of 3-(1- $\beta$-D-glucosyloxy) pyridazine was readily hydrolyzed by the acid or the enzyme, while $2-(1-\beta$-D-glucosyl) pyridazinone-(3) was stable under these conditions.

\section{Metabolism}

Figure 2 shows that there are 4 metabolites clearly detected in the ethanol extracts of barley shoots. Three of them were chromatographically assigned as 3-( $2^{\prime}$-methylphenoxy) pyridazine-1-oxide (M1), 3-pyridazinone- $(2 \mathrm{H})$

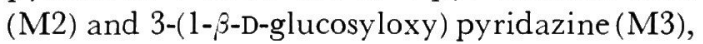
as shown in Table I. M4 is unknown and no further attempt has been made to determine the structure mainly because it was produced in very small amounts. The minute spot detected just above $\mathrm{H}-722$ in A and B of Fig. 2 is also unknown. This, however, is thought to be 0 -cresol metabolized from $\mathrm{H}-722$, since the $R f$ value of $o$-cresol was just above that of $\mathrm{H}-722$ in both systems. Although tritium labeling of $\mathrm{H}-722$ was done by catalytic reduction of the 6 -chloro analogue with

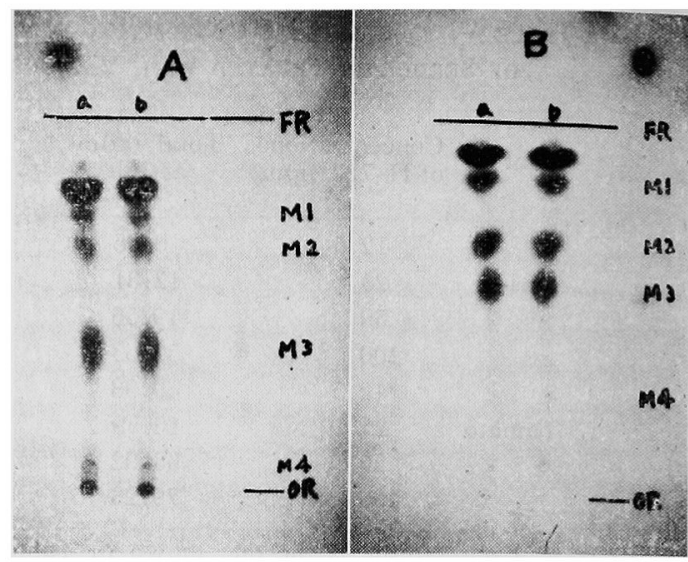

FIG. 2. Autoradiograms of Thin-layer Chromatograms of $\mathrm{H}-722$ and its Metabolites.

Ethanol extracts of barley shoots at the lst to 2nd leaf stage of growth. Roots were dipped in $100 \mathrm{ppm} \mathrm{H}-722$ solution $(2.0 \mathrm{mCi} / \mathrm{mg}$ ) for 2 days (a) and 4 days (b).

A: benzene: ethanol: chloroform $(1: 2: 2, \mathrm{v} / \mathrm{v} / \mathrm{v})$.

B: $n$-butanol: acetic acid: water $(4: 1: 5, \mathrm{v} / \mathrm{v} / \mathrm{v})$, upper layer.

tritium gas in the presence of palladiumcharcoal, some exchange reactions between tritium and the hydrogen in the molecule might have simultaneously taken place to a small extent. Radioactive compounds detected in tomato shoot extracts were the same as those in barley from a comparison of their

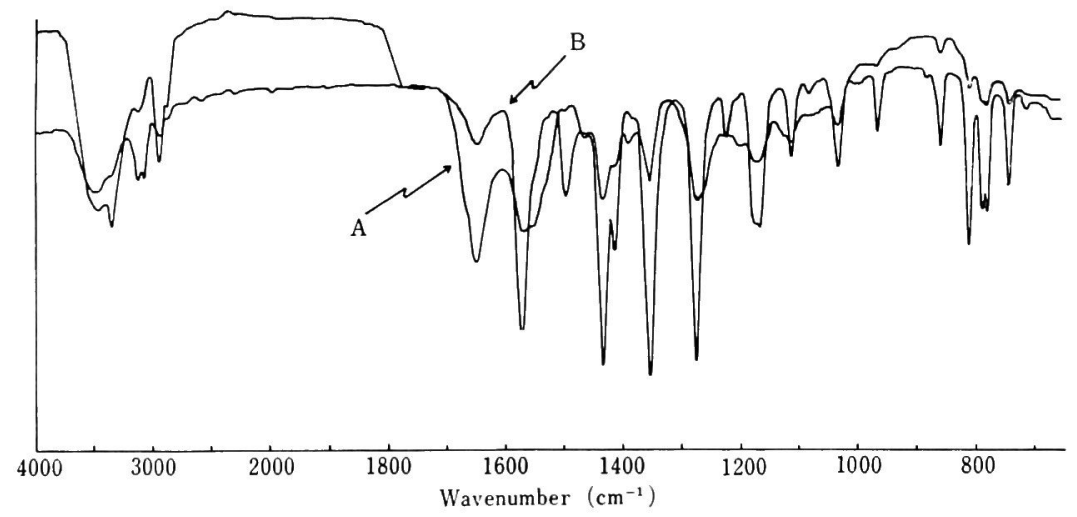

FIG. 3. Infrared Spectra of 3-(2'-Methylphenoxy) pyridazine-1-oxide. (KBr pellets) A: metabolite, B: synthetic material. 
$R f$ values in TLC system A, B and C (Table I). No other radioactive spots were detected. Almost all radioactivity in the ethanol extracts of roots from both species were chromatographically assigned as unchanged $\mathrm{H}-722$.

The IR spectrum of isolated Ml did not give sufficient information to assign it a structure, although its absorption pattern was similar to that of the authentic specimen (Fig. 3). Mass spectra of the metabolite and the authentic sample, however, were in good agreement (Fig. 4), therefore Ml was tentatively assigned as $3-\left(2^{\prime}\right.$-methylphenoxy) pyridazine-1-oxide. Jojima and Konotsune ${ }^{6}$ found that this compound was readily prepared by heating $\mathrm{H}-722$ with hydrogen peroxide, with no production of the corresponding 2-oxide. Thus, H-722 may be metabolized to the oxide by some peroxidase(s) in the plants. IR spectra of metabolite M2 and acetylated M3 supported their identification as 3-pyridazinone- $(2 \mathrm{H})$ and 3-(tetraacetyl-1- $\beta$-D-glucosyloxy)pyridazine, respectively (Figs. 5 and 6 ).

Since detection of 3-pyridazinone- $(2 \mathrm{H})$, as well as its glucoside, is indicative of cleavage of the aromatic $\epsilon$ ther linkage in $\mathrm{H}-722$, then o-cresol should be a resultant metabolite. However, the fate of this moiety after cleavage was not traced due to the lack of label.

Table $\mathrm{V}$ indicates that metabolism by barley seedlings was greater than by tomato under the same conditions. In barley, M3 was a
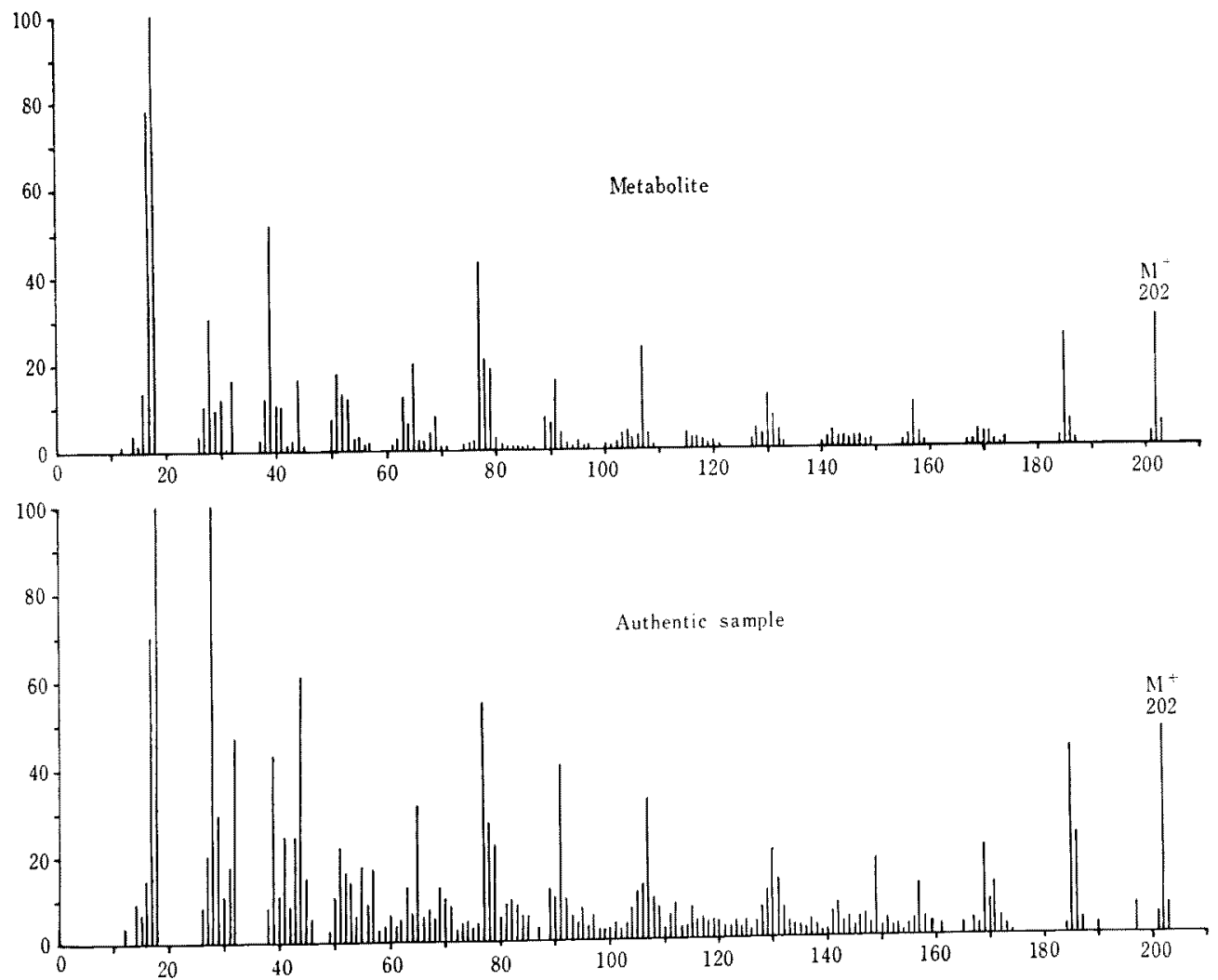

FIG. 4. Mass Spectra of 3-(2'-Methylphenoxy) pyridazine-1-oxide.

6) T. Jojima, Personal communication. 


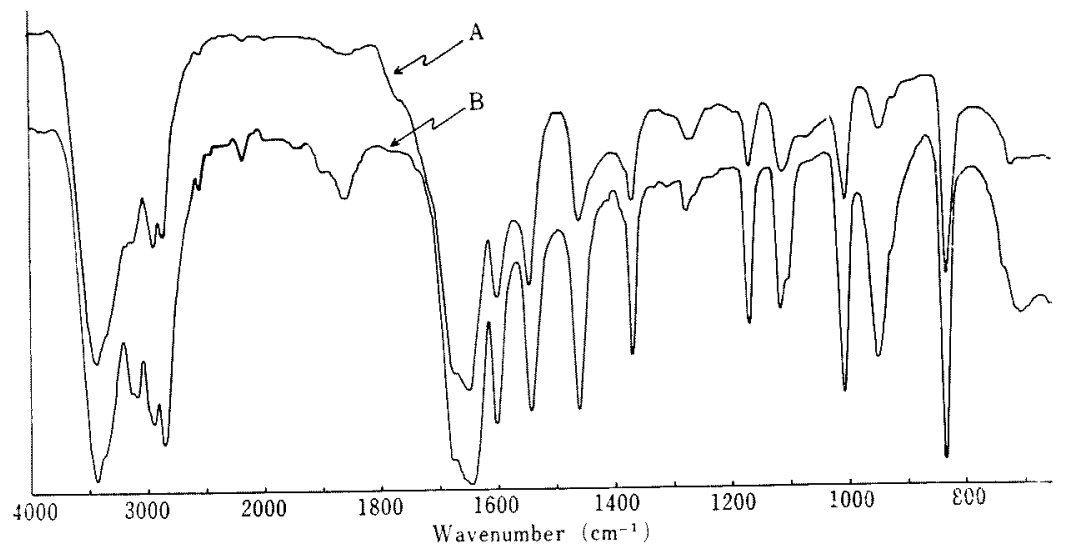

FIG. 5. Infrared Spectra of 3-Pyridazinone-(2H) (KBr pellets). A: metabolite, $\mathrm{B}$ : synthetic material.

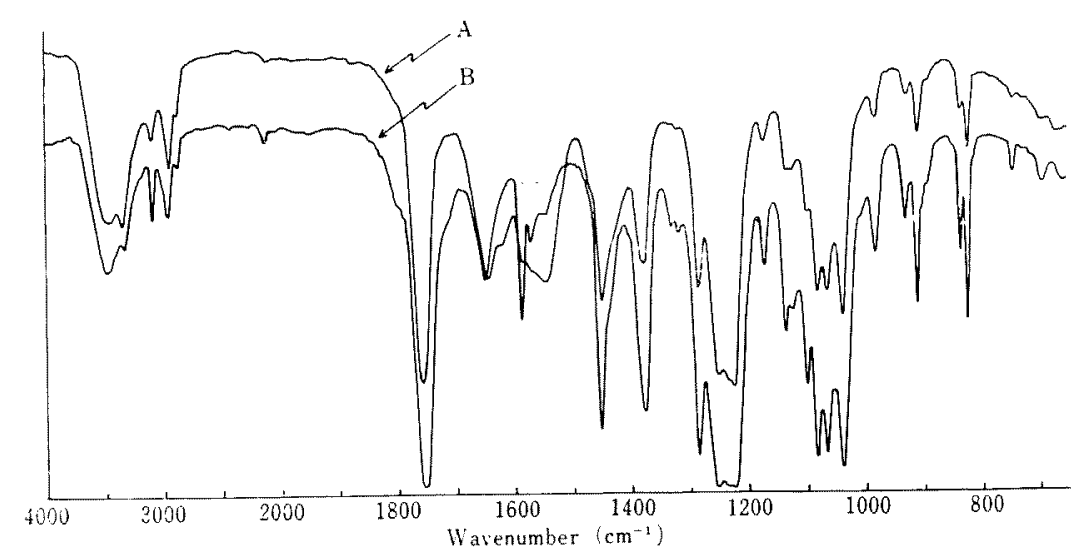

FIG. 6. Infrared Spectra of 3-(Tetraacetyl-1-3-D-glucosyloxy) pyridazine. (KBr pellets) A: metabolite, B: synthetic material.

major metabolite, and M1 and M2 were minor, while M2 as well as M3 were major in tomato. M4 was minute in both cases. Table VI shows the percent compositions of H-722 and the metabolites produced in the germination stage of the two plants. Metabolism in barley was also greater than in tomato in both treatment periods. M3 was a major metabolite, while M4 was almost undetectable in both species. Percent compositions of M1 and M2 were greater in tomato than in barley in both treatment periods.
Summarizing the above results, possible metabolic pathways of $\mathrm{H}-722$ are proposed in Fig. 7.

\section{Biological activity}

Figure 8 shows that barley is more sensitive to $\mathrm{H}-722$ than tomato in their germination stages, and characteristic inhibition is observed in their root growth. $\mathrm{H}-722$ does not require sunlight energy to exhibit its root growth inhibitory action (Table VIII).

$3-(2$ '-Methylphenoxy) pyridazine-1-oxide was 


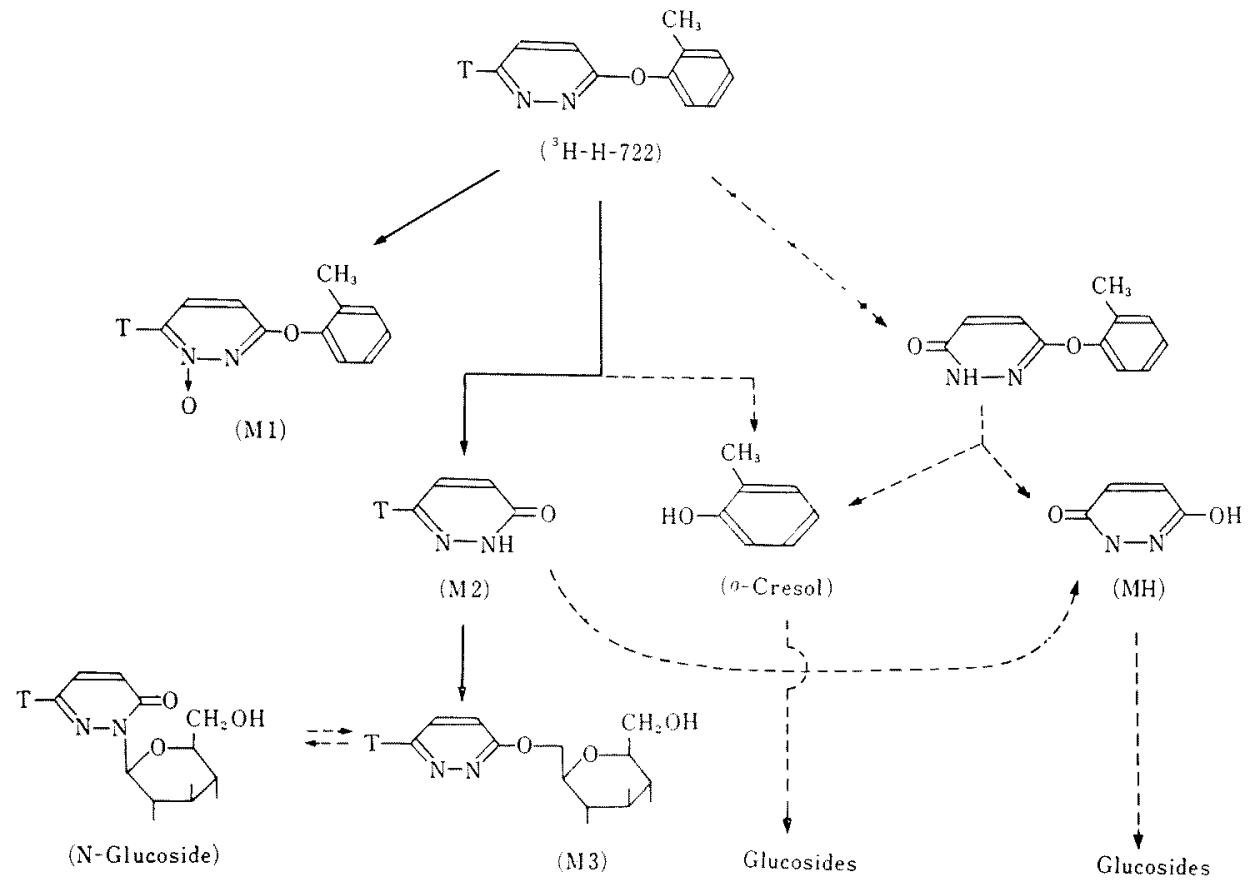

FIG. 7. Possible Pathways in 3-(2'-Methylphenoxy)pyridazine Metabolism. $--\rightarrow$ possible, but undetectable in this study.

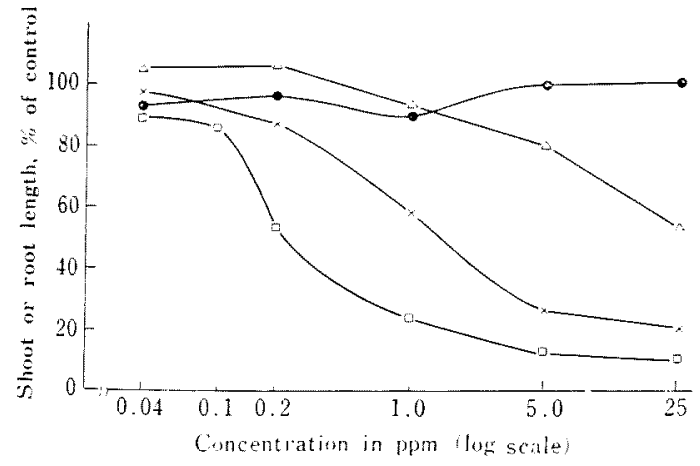

FIG. 8. Pre-emergence Herbicidal Activities of $\mathrm{H}$ 722 Estimated by the Petri Dish Method.

- shoot
$\times$ root $)^{\text {tomato }} \triangle$ shoot barley

active toward both species, but less active than $\mathrm{H}-722$. Its herbicidal selectivity between barley and tomato was quite similar to that of $\mathrm{H}-722$ (Fig. 9).
Table VIII. SUnlight Energy and Herbicidal ACTIVITY

\begin{tabular}{lcc}
\multicolumn{2}{l}{$\begin{array}{l}\text { Concentration of } \\
\text { H-722 }\end{array}$} & \multicolumn{2}{c}{ Barley root growth } \\
& Light & Darkat \\
\hline 1.0 & 17 & 18 \\
0.5 & 25 & 24 \\
0.25 & 41 & 41 \\
0 & 100 & 100 \\
\hline
\end{tabular}

a) Petri dishes were enveloped in thick black paper.

3-Pyridazinone- $(2 \mathrm{H})$ and its O-glucoside were poor in herbicidal activities (Figs. 10 and 11). Although their absorption and translocation properties were not investigated, they must be substantially inactive compounds. Scurfield ${ }^{7}$ reported that 3-pyridazinone- $(2 \mathrm{H})$ did not produce symptoms of damage similar to

7) G. Scurfield, Australian J. Sci., 24, 417 (1962). 


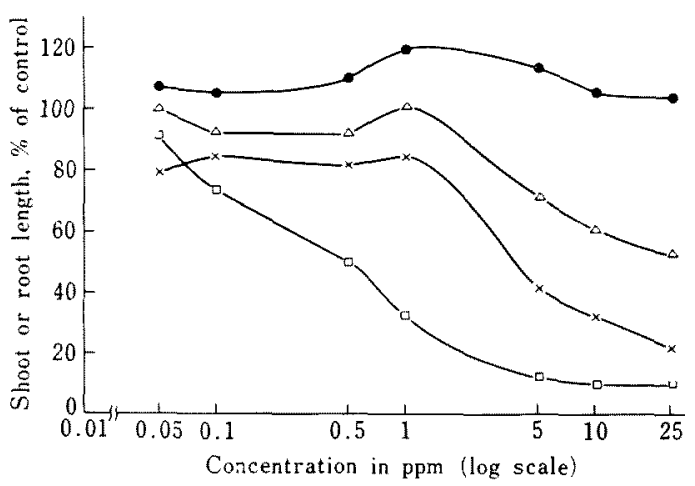

FIG. 9. Pre-emergence Herbicidal Activities of 3(2'-Methylphenoxy)pyridazine-1-oxide Estimated by the Petri Dish Method.

- shoot tomato $\triangle$ shoot
$\square$ root

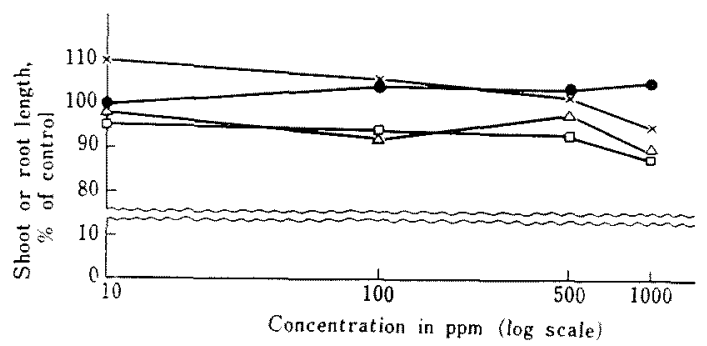

FIG. 10. Pre-emergence Herbicidal Activities of 3Pyridazinone- $(2 \mathrm{H})$ Estimated by the Petri Dish Method.

$$
\text { - } \left.\begin{array}{l}
\text { shoot tomato } \triangle \text { shoot } \\
\square \text { root }
\end{array}\right\} \text { barley }
$$

those produced by maleic hydrazide when applied to plants of Phalaris carrariensis L. and of $P$. tuberosa L. at the $1 \mathrm{st} \sim 2$ nd mature leaf stage.

Maleic hydrazide was active against both species, especially in inhibition of root elongation, but at a much higher dosage than $\mathrm{H}$ 722. A special property of this compound, however, was its higher toxicity to tomato than to barley, as shown in Fig. 12. Absorption and translocation properties of the compound have been demonstrated in some

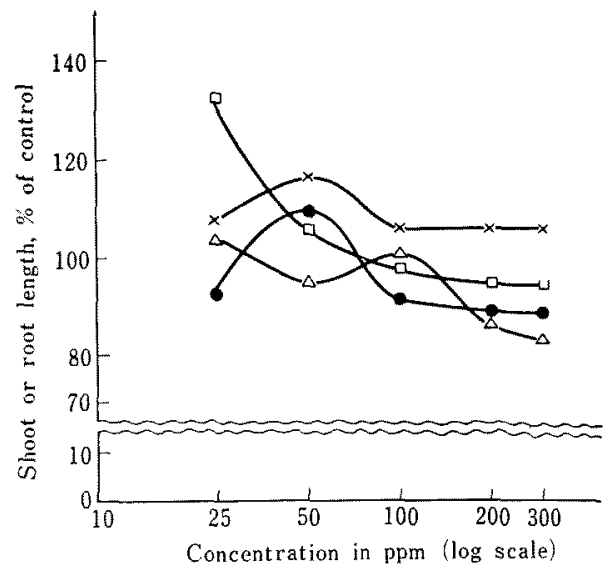

FIG. 11. Pre-emergence Herbicidal Activities of 3-(1$\beta$-D-Glucosyloxy)pyridazine Estimated by the Petri Dish Method.

$$
\left.\left.\begin{array}{l}
\text { - shoot } \\
\text { root }
\end{array}\right\} \text { tornato } \triangle \text { shoot } \begin{array}{l}
\square \text { root }
\end{array}\right\} \text { barley }
$$

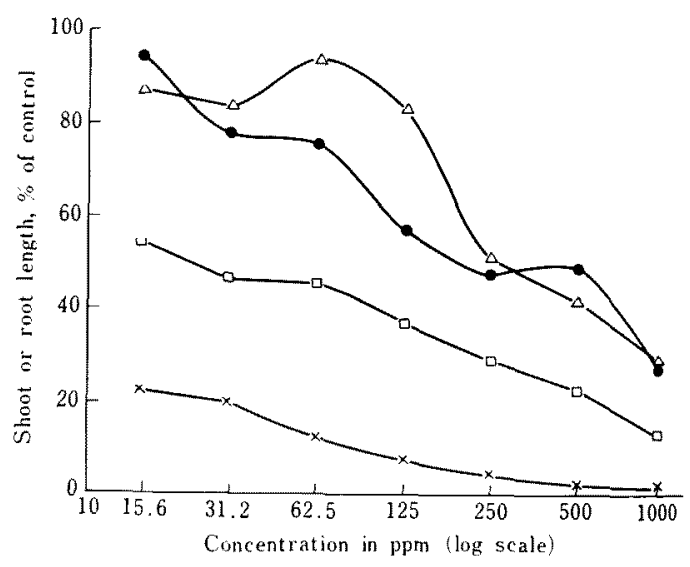

FIG. 12. Pre-emergence Herbicidal Activities of Maleic Hydrazide Estimated by the Petri Dish Method.

$$
\left.\left.\begin{array}{l}
\text { shoot } \\
x \text { root }
\end{array}\right\} \text { tomato } \triangle \begin{array}{c}
\Delta \text { shoot } \\
\square \text { root }
\end{array}\right\} \text { barley }
$$

plants. $^{8.9}$

Herbicidal activity of $o$-cresol was extremely

8) H. Martin, "Guide to the Chemicals used in Crop Protection," 4th ed. (Canada Dept. of Agriculture, 1961).

9) G. H. N. Towers, A. Hutchinson and W. A. Andreae, Nature, 181, 1535 (1958). 


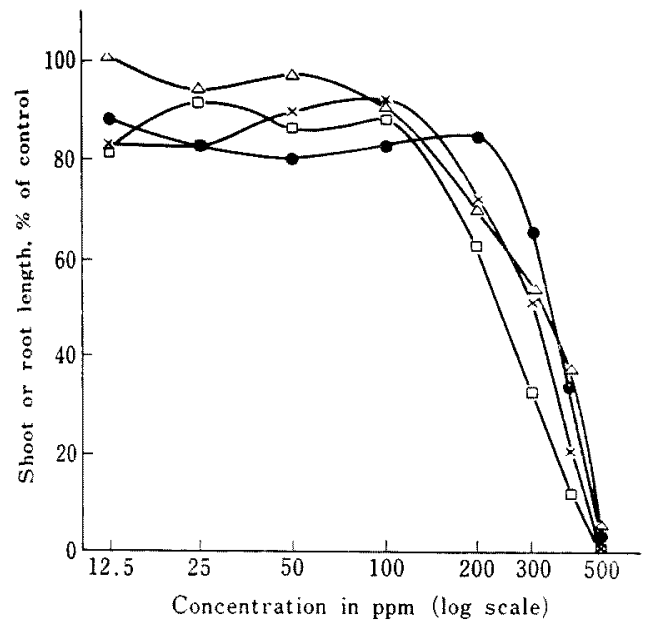

FIG. 13. Pre-emergence Herbicidal Activities of 0 -

Cresol Estimated by the Petri Dish Method.

$$
\left.x \text { root } \begin{array}{l}
\text { shoot } \\
\text { romato } \triangle \text { shoot } \\
\square \text { root }
\end{array}\right\} \text { barley }
$$

low, i.e. more than $200 \mathrm{ppm}$ of the sample concentration was required for distinct growth inhibition in either species (Fig. 13).

Observation of the 1st to 2nd leaf growth stage in plants which were treated with 25 to $200 \mathrm{ppm}$ of $\mathrm{H}-722$ in nutrient solution in the greenhouse, showed that both species began to perish from the tips of the leaves after 10 days at the $75 \mathrm{ppm}$ (barley) and $200 \mathrm{ppm}$ (tomato) treatment level. Therefore, $\mathrm{H}-722$ is considered to be active against plants in their seedling stage of growth and the two species showed the same relative sensitivity as in their germination stages.

\section{DISCUSSION}

The isotope recovery experiment is especially important in studies of metabolism with this labeled chemical, since the chemical is expected to be metabolized to maleic hydrazide, which is a well known plant growth regulator. ${ }^{810}$ Thus, the tritium label at the

10) D. L. Schene and O. L. Hoffman, Science, 109, 508 (1949). 6-position of the pyridazine ring would be lost in the form of tritiated water. Consequently, no maleic hydrazide produced can be traced. 3-(2'-Methylphenoxy) pyridazine6 -one- $(1 \mathrm{H})$ may be another compound, which may also readily loose its label when metabolized from labeled $\mathrm{H}-722$, although this compound is only slightly herbicidally active. ${ }^{21}$ However, metabolism of $\mathrm{H}-722$ to these compounds must be negligible in seedling stages of both species, since isotope recoveries after removing water were high in all experiments and since we found that differences in isotope recovery were not correlated with treatment time, sample concentration, or the type of plant used (Tables II and III). Isotope recoveries in germination stages of growth were also high, reaching $95 \%$ or more in both plant species (Table IV).

Recently Jojima and Kawakubo found that 3-(2'-methylphenoxy)-6-methylpyridazine also had selective herbicidal action against barley. ${ }^{11}$, This does not support a mechanism which attributes the herbicidal activity of these phenoxypyridazines to such metabolites as maleic hydrazide arising from the attack on the 6-position of the pyridazine ring, since metabolic demethylation of the compound is quite improbable.

A detailed mechanism for the selective action of $\mathrm{H}-722$ on these plants was not elucidated by these studies. However, some information on this point was obtained. Data (Tables $\mathrm{V}$ and $\mathrm{VI}$ ) show that the sensitivity of these species to $\mathrm{H}-722$ is not correlated with their total load of radioactivity or with the amount present of the five compounds extracted from the plant tissues by ethanol. Results show that $\mathrm{H}-722$ was always absorbed more into tomato than into barley in the seedling stage as well as the germination stage, when compared on either a fresh or a dry weight basis. The lower metabolic rate in

11) T. Jojima and K. Kawakubo of Sankyo Co., Ltd., Unpublished work. 
tomato than in barley in both stages of growth, seems to indicate that the selective action of the herbicide is not due to a concentration difference between the two species of the parent compound or activation products in the plants.

Among the compounds detected as metabolites, 3-(2'-methylphenoxy) pyridazine-1-oxide was the most active and specific to barley; however, its percent of composition as well as the absolute content on a weight basis was smaller in barley than in tomato. Therefore, this metabolite may not be the key compound to selective action. Ortho-cresol, which is thought to be one of the major metabolites in both species, was more toxic to barley than to tomato. However, it is also doubtful that selective action could be simply attributed to this compound, because it is an extremely weak herbicide and its absolute content is calculated from the quantity of M2 plus M3 in each experiment to be smaller in barley than in tomato.

Jojima and Konotsune ${ }^{12}$ performed a regression analysis of herbicidal activities of the 3-phenoxypyridazines, including $\mathrm{H}-722$, on their stability to hydrolysis by an acid medium as one of the factors. They pointed out that one of the important factors in the herbicidal potency of these compounds was a suitable tendency to cleave at their aromatic ether linkages.

This suggests that the herbicidal action of $\mathrm{H}-$ 722 might not be due to $\mathrm{H}-722$ itself but to some activated metabolite(s). If so, the selective action between the two species might be attributed to differences in the fate and behavior of 0 -cresol in both species. 0 -Cresol might be continuously generated at some place in the cell, where vital functions are being conducted, and detoxication of 0 -cresol (or its biologically active metabolite). i.e. for-

12) T. Jojima and T. Konotsune, Abstr., Papers, American Chemical Society 1969, No. 158, Pesticide Chemistry No. 33. mation of sugar conjugates, might take place to a lesser extent or more slowly in barley than in tomato; consequently, the vital functions of the former might be strongly inhibited.

On the other hand, $\mathrm{H}-722$ itself may be the active form and selective action may be due to a factor such as difference in enzyme sensitivity between the two species; provided $\mathrm{H}-722$ is an enzyme inhibitor. Or, it might cause some other physiological dysfunction in the susceptible plant, as in the case of 2,4dichlorophenoxyacetic acid which causes some susceptible plants to suffer abnormal nucleic acid synthesis. ${ }^{13,141}$

Interestingly, the aromatic ether linkage of $\mathrm{H}-722$ is readily cleaved in plants, perhaps enzymatically. Since H-722 can be structually classified as a diphenylether herbicide, this result may extend also to the metabolism of other diphenylethers, i.e. 2, 4-dichlorophenoxy$4^{\prime}$-nitrobenzene (NIP) and 2, 4,6-trichlorophenoxy-4'-nitrobenzene (MO 338). But, the mode of action of $\mathrm{H}-722$ must be considered to belong to a different category, because $\mathrm{H}$ 722 (which has a substituent at the ortho position of the benzene ring) has herbicidal action regardless of the presence or absence of light energy (Table VIII). Other diphenylethers have been clearly classified into two groups; one having at least one substituent at the ortho positions of one benzene ring requires light energy to activate its herbicidal activity and the other group having no substituents at the ortho positions is active even in the dark. ${ }^{15,16)}$

Acknowledgments. We thank Dr. T. Jojima for providing us with authentic samples of the related compounds of H-722 and for his valuable discussions

13) J. B. Hanson and F. W. Slife, Residue Review, 25, 59 (1969).

14) J. Cardenas, F. W. Slife, J. B. Hanson and H. Butler, Weed Sci, 16, 96 (1968).

15) S. Matsunaka, Residue Review, 25, 45 (1969).

16) S. Matsunaka, J. Agr. Food Chem., 17, 171 (1969). 
during the course of this work. We are also grateful to Dr. G. Kuwata and Mr. M. Morimoto for their constant encouragement. We also wish to acknow- ledge the technical assistance of Messrs. T. Okazaki and M. Ando, and Miss S. Iwasaki, and the critical review of this manuscript by Mr. T. J. Leffingwell. 